\title{
Avaliação sob Pastejo do Potencial Forrageiro de Gramíneas do Gênero Cynodon, sob Dois Níveis de Nitrogênio e Potássio
}

\author{
Maurilio José Alvim ${ }^{1}$, Milton de Andrade Botrel ${ }^{1}$, Humberto Rezende ${ }^{2}$, Deise Ferreira Xavier ${ }^{1}$
}

RESUMO - O trabalho foi conduzido no Município de Coronel Pacheco - MG (Embrapa Gado de Leite), com objetivo de avaliar, em condições de pastejo, o capim-estrela-africana (Cynodon nlemfuensis, Vanderyst) e três cultivares de Cynodon dactylon, L. Pers. (Florona, Florakirk, Florico), adubadas com N: $\mathrm{K}_{2} \mathrm{O}$, nas dosagens de 250:200 ou 500:400 kg/ha/ano. O delineamento experimental foi o de blocos ao acaso, com parcelas subdivididas e três repetições. Não houve diferenças significativas nas produções de massa seca (MS) em função das dosagens de $\mathrm{N}$ aplicadas. Nas duas dosagens de $\mathrm{N}: \mathrm{K}_{2} \mathrm{O}$, a produção anual de MS da Florakirk foi a mais elevada, porém com baixa produção na época da seca. A cultivar Florico foi a de menor produção de MS. As cultivares Florona e Florakirk proporcionaram a melhor e a pior distribuição estacional de forragem, respectivamente. As doses de $\mathrm{N}: \mathrm{K}_{2} \mathrm{O}$ e as épocas do ano não influenciaram nos teores de $\mathrm{PB}$, que foram diretamente proporcionais à relação folha-colmo da planta. Os maiores teores de $\mathrm{PB}$ foram proporcionados pela cultivar Florakirk, enquanto os menores pelo capim-estrela-africana e cultivar Florico. A DIVMS da forragem produzida na época das chuvas foi ligeiramente superior à da época da seca. Não houve influência das dosagens de $\mathrm{N}: \mathrm{K}_{2} \mathrm{O}$ sobre a DIVMS, que foi mais elevada na forragem produzida pelas cultivares Florakirk e Florona.

Palavras-chave: Cynodon nlenfuensis,Cynodon dactylon, digestibilidade da massa seca, produção de massa seca, proteína bruta, relação folha-colmo

\section{Evaluation under Grazing of Forage Potential of Cynodon Grass under Two Nitrogen and Potassium Levels}

\begin{abstract}
The study was undertaken in Coronel Pacheco - MG (National Dairy Cattle Reserch Center of the Brazilian Agricultural Corporation - EMBRAPA), to evaluate, under grazing conditions, the Cynodon nlenfuensis, Vanderyst and three cultivars of Cynodon dactylon, L. Pers. (Florona, Florakirk, Florico), fertilized with either 250:200 or 500:400 kg/ha/year of N: $\mathrm{K}_{2} \mathrm{O}$. The experimental design was a randomized blocks, in split-plot, and three replications. No significant difference on dry matter yield between the two rates of $\mathrm{N} / \mathrm{K}_{2} \mathrm{O}$ were found. In both $\mathrm{N}: \mathrm{K}_{2} \mathrm{O}$ rates, Florakirk cultivar presented the highest annual dry matter yield, however, in the dry season it showed a low yield level. The Florico was the cultivar with the lowest dry matter yield. The best and the worst forage distribution were exhibited by cultivars Florona and Florakirk, respectively. The CP contents in the forage was not influenced by either nitrogen rates or season, and directly related to the leaf-stem ratio. The highest CP contents were found in Florakirk, while the lowest in african stargrass grass and Florico cultivar. The IVDMD of forage produced during the rainy season was slightly superior to those of the dry season. The $\mathrm{N}: \mathrm{K}_{2} \mathrm{O}$ rates did not influence IVDMD, which were higher in Florakirk and Florona cultivars.
\end{abstract}

Key Words: Cynodon nlemfuensis, Cynodon dactylon, in vitro dry matter digestibility, dry matter yield, crude protein, leaf-stem ratio

\section{Introdução}

Nos Estados Unidos, algumas cultivares de gramíneas forrageiras do gênero Cynodon foram lançadas, resultantes de pesquisas em melhoramento genético, realizadas nas Universidades da Geórgia e da Flórida. Entre as mais promissoras, destacaram-se as cultivares Florona, Florico e Florakirk, que, naquele país, proporcionam elevadas quantidades de forragem de boa qualidade e apresentam resistência a pragas e doenças e a baixa temperatura (Mislevy, 1989a; 1989b, 1995). Diante disso, essas plantas forrageiras são recomendadas para sistemas de produção animal em pastagem, sendo muito usadas no sul e sudeste daquele país.

Baseando-se nas informações da pesquisa realizada nos Estados Unidos, empresas privadas do Brasil importaram essas gramíneas e as recomendam para sistemas de produção animal no país. Contudo, as potencialidades forrageiras de uma espécie podem variar de uma região para outra, em função das diferenças que ocorrem em suas condições

\footnotetext{
${ }^{1}$ Pesquisador da Embrapa - Centro Nacional de Pesquisa de Gado de Leite (CNPGL), Rua Eugênio do Nascimento, 610, Dom Bosco, CEP: 36038-330, Juiz de Fora, MG. Bolsista do CNPq.E.mail: alvim@cnpgl.embrapa.br; mbotrel@cnpgl.embrapa.br; dfxavier@cnpgl.embrapa.br 2 Técnico de nível superior da Embrapa-CNPGL. E.mail: rezende@cnpgl.embrapa.br
} 
edafoclimáticas (Botrel et al., 1998). Baseando-se nisso, antes de introduzir nas propriedades rurais uma espécie pouco conhecida, é necessário que essa seja avaliada pela pesquisa, para que se possa conhecer melhor a sua adaptação e, consequentemente, o seu potencial forrageiro na região onde será estabelecida.

Além da necessidade da planta ser adaptada às condições climáticas da região, o seu potencial forrageiro é maximizado quando a fertilidade do solo atende as suas exigências. Neste sentido, o N e o $\mathrm{K}$ são de muita importância, por se tratar de nutrientes que garantem o crescimento da planta. Portanto, para se maximizar a produção de forragem da gramínea, estes elementos devem estar disponíveis no solo, nas dosagens necessárias (Alvim et al., 1998 e 1999).

Diante de pesquisas realizadas nas condições edafoclimáticas da região, o potencial da planta forrageira é conhecido e, consequentemente, o planejamento da propriedade, no que se refere à produção de leite em pastagem, fica mais confiável, com redução nos riscos aos quais os sistemas de produção estão sujeitos. Isto torna-se mais importante, quando se trata de pastagens constituídas por espécies que apresentam elevado potencial forrageiro, pois possibilitará ao produtor menor necessidade de concentrado ou de forragens conservadas para alimentar o seu rebanho, com conseqüente redução nos custos da produção animal (Vilela et al., 1996).

O presente trabalho foi conduzido com o objetivo de avaliar, em condições de pastejo, o potencial forrageiro do capim-estrela-africana e das cultivares Florona, Florico e Florakirk, adubadas com duas doses de $\mathrm{N}: \mathrm{K}_{2} \mathrm{O}$.

\section{Material e Métodos}

O experimento foi conduzido em área experimental da Embrapa Gado de Leite, localizada em Coronel Pacheco, MG, $\left(21^{\circ} 35^{\prime} 08^{\prime \prime}\right.$ de latitude Sul e $43^{\circ} 15^{\prime}$, 04 " de longitude oeste), no período de setembro de 1998 a setembro de 2000, correspondendo a duas épocas de seca, com baixa temperatura, e duas de chuvas, de temperatura elevada.

O clima da região é do tipo Cwa (mesotérmico), definido como subtropical, chuvoso no verão e seco no inverno. A precipitação média anual é próxima de 1.500 $\mathrm{mm}$, distribuídos irregularmente, com cerca de $200 \mathrm{~mm}$ de precipitação ocorrendo no período da seca (maio a setembro). Nos últimos dez anos, a temperatura média anual foi de $19,5^{\circ} \mathrm{C}$ e a precipitação, de $1.520 \mathrm{~mm}$.
Os tratamentos consistiram de avaliações do Cynodon nlenfuensis, Vanderyst (capim-estrelaafricana), considerado padrão, e de outras três gramíneas da espécie Cynodon dactylon, L. Pers. (cultivares Florona, Florico e Florakirk). Cada uma dessas gramíneas foi submetida a duas doses de $\mathrm{N}: \mathrm{K}_{2} \mathrm{O}$, numa relação igual a 0,8 , o que correspondeu a 250:200 e 500:400 kg/ha/ano. O nitrogênio (sulfato de amônio) e o potássio (cloreto de potássio) foram misturados na proporção definida $\left(\mathrm{N}: \mathrm{K}_{2} \mathrm{O}=0,8\right)$, divididas em cinco doses e aplicados em superfície em setembro, novembro, janeiro, março e maio.

O plantio das plantas forrageiras foi realizado em março de 1997, imediatamente após o preparo do solo, utilizando-se mudas distribuídas em sulcos, com espaçamento de $50 \mathrm{~cm}$ entre eles. Por ocasião do preparo do solo, foi feita a adubação fosfatada (superfosfato simples), na dosagem de $80 \mathrm{~kg} / \mathrm{ha}$, realizada a lanço, com incorporação ao solo à profundidade de até $20 \mathrm{~cm}$.

No momento do preparo do solo e plantio das plantas forrageiras, o solo apresentava as seguintes características químicas: $\mathrm{pH}$ emágua $(1: 2,5)=5,8 ; \mathrm{P}=16,7 \mathrm{mg} / \mathrm{dm}^{3}$; $\mathrm{K}=71,4 \mathrm{mg} / \mathrm{dm}^{3} ; \mathrm{Al}=0,6 \mathrm{cmol}_{\mathrm{c}} / \mathrm{dm}^{3} ; \mathrm{Ca}=0,7 \mathrm{cmol}_{\mathrm{c}} / \mathrm{dm}^{3}$; $\mathrm{Mg}=0,32 \mathrm{cmol}_{\mathrm{c}} / \mathrm{dm}^{3} ;$ e $\mathrm{MO}=2,1 \mathrm{mg} / \mathrm{dm}^{3}$.

Foi adotado o delineamento experimental de blocos completos ao acaso, com parcelas subdivididas, e três repetições. Nas parcelas $\left(2.000 \mathrm{~m}^{2}\right)$, foram alocadas as cultivares e nas subparcelas $\left(1.000 \mathrm{~m}^{2}\right)$ as dosagens de $\mathrm{N}: \mathrm{K}_{2} \mathrm{O}$.

As plantas forrageiras foram avaliadas conforme métodos de Edye (1975) e Gardner (1983) e adotada em pesquisa realizada por Botrel et al. (1987), a qual permite que se avaliem plantas forrageiras sob os efeitos do pastejo e do pisoteio animal.

Em setembro de 1998, 18 meses após o plantio, admitiu-se que as quatro forrageiras a serem avaliadas estavam estabelecidas, pois apresentavam completa cobertura vegetal do solo. Neste momento, foi realizado um corte de uniformização em toda a área experimental.

A partir do corte de uniformização, foram feitas avaliações semanais de disponibilidade de forragem em cada subparcela, através de amostragens constituídas por lançamentos ao acaso de quadrados de 0,5 $\mathrm{m}$ de lado, quatro vezes por subparcela. A forragem colhida no interior do quadrado (cortada a $8-10 \mathrm{~cm}$ acima do nível do solo) era secada a $65^{\circ} \mathrm{C}$, com a quantidade de massa seca (MS) obtida sendo correlacionada com a altura do pasto, medida no interior do quadrado. Essas amostragens semanais 
foram realizadas até que a disponibilidade de MS em um dos piquetes atingisse $4.000 \mathrm{~kg} / \mathrm{ha}$, na época das chuvas, quando iniciou-se o primeiro pastejo em todas as plantas forrageiras.

Daí em diante, após cada pastejo, as disponibilidades de MS das subparcelas foram monitoradas, semanalmente, através da altura do pasto. Sempre que a altura do pasto em um dos piquetes indicava a disponibilidade de MS próxima de 4.000 e $2.500 \mathrm{~kg} /$ ha, respectivamente, nas épocas das chuvas e da seca, todas as forrageiras eram pastejadas individualmente, usando-se novilhas da raça Holandesa.

A quantidade de forragem residual também foi correlacionada com a altura do pasto, diariamente, durante o primeiro pastejo, à semelhança do critério adotado para correlacionar a altura do pasto com a disponibilidade de MS. Cada pastejo teve duração máxima de três dias, com os animais sendo retirados dos piquetes assim que a forragem residual atingia cerca de 2.000 e $1.000 \mathrm{~kg} /$ ha de MS, respectivamente na época das chuvas e da seca. O número de animais por piquete, variava em função da época do ano e da disponibilidade de forragem existente nos piquetes.

Os intervalos dos pastejos dependeram do tempo necessário para que, em pelo menos uma subparcela fosse atingida novamente a disponibilidade de forragem preestabelecida, que, em média, ocorreu a intervalos que variaram de 25 dias na época das chuvas a 45 dias na época da seca.

Sempre que a altura do pasto indicasse o momento de realizar o pastejo ou o momento de retirar os animais dos piquetes, foram realizadas, na véspera de entrada dos animais nos piquetes e no dia seguinte à retirada dos animais, amostragens com lançamentos de quadrados à semelhança do que foi feito no início do experimento. Toda a vegetação recolhida do interior do quadrado, foi usada para estimar as quantidades de MS produzida e para conferir a correlação entre a quantidade de forragem existente no piquete e a altura do pasto. A diferença entre a quantidade de massa seca residual estimada no dia seguinte póspastejo e a quantidade de massa seca disponível estimada na véspera do próximo pastejo serviu para estimar o acúmulo de MS correspondente ao período entre pastejos. Com o somatório dessas estimativas periódicas obteve-se a produção anual de MS. Além disso, o material recolhido do interior do quadrado foi também usado, uma vez por época das chuvas e outra por ocasião da seca, para as avaliações dos teores de proteína bruta (PB) pelo método de Kjeldahl (AOAC,
1984), digestibilidade in vitro da MS (DIVMS), conforme Tilley \& Terry (1963) e relação folha:colmo, baseada na MS. Neste trabalho, foram estimadas, também, a cobertura vegetal do solo e a composição botânica, em toda área experimental. Essas estimativas foram realizadas visualmente, nas vésperas do corte de uniformização (setembro de 1998) e do último pastejo (setembro de 2000), usando a metodologia de lançamento ao acaso do quadrados de $0,5 \mathrm{~m}$ de lado, quatro vezes por piquete. Três observadores analisavam individualmente o interior do quadrado e anotavam a presença, em porcentagem, dos seguintes grupos: Forrageira em avaliação, braquiária, espécies de folhas largas, outras gramíneas e solo descoberto.

Nas subparcelas, os animais tiveram a disposição água, sal mineral e sombra. O manejo das pastagens foi realizado com o auxílio de cerca elétrica, que individualizaram as subparcelas.

Não houve efeito de anos e por essa razão a análise estatística dos resultados foi feita com base na média dos dois anos de condução do experimento, conforme o desenho experimental adotado, usandose o SAS a $1 \%$ de significância.

\section{Resultados e Discussão}

As adubações $\mathrm{N}: \mathrm{K}_{2} \mathrm{O}$ realizadas resultaram em produções semelhantes $(\mathrm{P}>0,05)$ de MS (anual e estacionais), sem também afetarem a distribuição de forragem ao longo do ano (Tabela 1).

Em ambas as dosagens de $\mathrm{N}: \mathrm{K}_{2} \mathrm{O}$, a cultivar Florakirk foi a que proporcionou maior quantidade anual de MS $(\mathrm{P}<0,05)$, porém com produção semelhante à da cultivar Florona. No entanto, no período da seca, a sua produção foi muito baixa $(\mathrm{P}<0,05)$, o que significa forte desvantagem em termos de distribuição de forragem ao longo do ano. Essa má distribuição de forragem observada para a cultivar Florakirk pode estar associada à maior sensibilidade dessa planta forrageira aos fatores adversos para o crescimento vegetativo que, durante a época da seca, prevalecem na Região Sudeste onde este estudo foi realizado, como baixa umidade no solo, pouca luminosidade e baixa temperatura. A cultivar Florona, além de ter produzido expressiva quantidade anual de MS, destacou-se por ter apresentado a melhor distribuição de forragem ao longo do ano $(\mathrm{P}<0,05)$. Por outro lado, a cultivar Florico foi a de menor produção de MS $(\mathrm{P}<0,05)$, tanto na época das chuvas quanto na 
Tabela 1 - Produção de MS (kg/ha) de cultivares de Cynodon, adubadas com 250:200 e 500:400 kg/ha de N: $\mathrm{K}_{2} \mathrm{O}^{1}$ Table 1 - Dry matter yield (kg/ha) of Cynodon cultivars, fertilized with 250:200 and 500:400 kg/ha of $\mathrm{N}: \mathrm{K}_{2} \mathrm{O}^{1}$

\begin{tabular}{|c|c|c|c|c|}
\hline \multirow[t]{2}{*}{ Cultivar } & \multicolumn{4}{|c|}{$\begin{array}{l}\mathrm{MS}(\mathrm{kg} / \mathrm{ha})^{2} \\
D M(k g / h a)^{2}\end{array}$} \\
\hline & $\begin{array}{c}\text { Chuvas } \\
\text { Rainy period }\end{array}$ & $\begin{array}{c}\text { Seca } \\
\text { Dry period }\end{array}$ & $\begin{array}{l}\text { Anual } \\
\text { Annual }\end{array}$ & $(\%)^{3}$ \\
\hline \multicolumn{5}{|c|}{$250: 200 \mathrm{~kg} /$ ha de $\mathrm{N}: \mathrm{K}_{2} \mathrm{O}}$. \\
\hline Florona & $12.349 b$ & $7.900 \mathrm{a}$ & $20.249 \mathrm{ab}$ & 39,0 \\
\hline Florakirk & $20.083 a$ & $4.817 \mathrm{~b}$ & $24.900 \mathrm{a}$ & 19,3 \\
\hline Estrela africana & $11.512 b$ & $6.697 \mathrm{a}$ & $18.609 \mathrm{~b}$ & 36,0 \\
\hline Florico & $9.649 b$ & $3.222 b$ & $12.871 \mathrm{c}$ & 25,0 \\
\hline \multirow{2}{*}{ Média (Mean) } & $13.398 \mathrm{~A}$ & $5.659 \mathrm{~A}$ & 19.157A & 29,8 \\
\hline & & $. .500: 400$ & $\mathrm{O} \ldots \ldots \ldots \ldots$ & \\
\hline Florona & $13.474 b$ & $9.983 \mathrm{a}$ & $23.457 \mathrm{ab}$ & 42,5 \\
\hline Florakirk & $22.291 \mathrm{a}$ & $5.421 \mathrm{~b}$ & $27.712 \mathrm{a}$ & 19,6 \\
\hline Estrela africana & $12.582 b$ & $8.557 \mathrm{a}$ & $21.739 b$ & 39,4 \\
\hline Florico & $8.897 \mathrm{c}$ & $3.004 \mathrm{c}$ & $13.901 \mathrm{c}$ & 20,1 \\
\hline Média (Mean) & $14.311 \mathrm{~A}$ & $6.741 \mathrm{~A}$ & $21.725 \mathrm{~A}$ & 30,4 \\
\hline $\mathrm{CV}(\%)$ & 22,19 & 21,42 & 15,96 & 17,63 \\
\hline
\end{tabular}

seca, não constituindo, assim, uma planta forrageira alternativa para sistema de produção de leite. Tanto a produção anual de MS quanto as produções estacionais do estrela-africana foram semelhantes $(\mathrm{P}>0,05)$ às da cultivar Florona (Tabela 1$)$.

Mislevy (1995, 1989a), aplicando menores doses de N, registrou na Flórida (Estados Unidos), menores produções anuais de MS para as cultivares Florakirk e Florona do que as obtidas no presente trabalho. Porém, no caso da cultivar Florakirk, o autor observou melhor distribuição de forragem ao longo do ano. Segundo Mislevy (1989b), a produção de MS da cultivar Florico naquele país também foi baixa, à semelhança do que se estimou no presente trabalho. Estudos de Alvim et al. (1998, 1999), conduzidos na mesma região onde foi executado o presente trabalho e com gramíneas também do gênero Cynodon (Tifton 85 e Coastcross-1), apresentaram produções de MS para o Coastcross -1 e para o Tifton 85 variando de 4,0 e 3,4 t/ha/ano, sem adubação nitrogenada, a 30 e 25 t/ha/ano, ao aplicar cerca de 600:480 kg/ha/ano de N e $\mathrm{K}_{2} \mathrm{O}$. Nestes estudos, a freqüência de cortes também interferiu na produção de MS dessas plantas forrageiras, já que os cortes a cada duas semanas resultaram em menores produções em relação aos cortes realizados a cada sete semanas. Em Cuba, onde predominam melhores condições de clima, Hernandez \& Cárdenas (1990) registraram maiores produções de MS para o capim-estrela-africana, com oscilações na produção em função da adubação aplicada.

Tratando-se de gramíneas tropicais, no geral, os teores de PB obtidos na forragem disponível das cultivares avaliadas foram expressivos. Em relação à aplicação de 250:200 kg/ha/ano de $\mathrm{N}: \mathrm{K}_{2} \mathrm{O}$, a aplicação de $500: 400 \mathrm{~kg} / \mathrm{ha} /$ ano de $\mathrm{N}: \mathrm{K}_{2} \mathrm{O}$ apresentou tendência de maiores conteúdos protéicos na MS dessas forrageiras. $\mathrm{Na}$ forragem disponível, tanto na época da seca quanto nas chuvas, a cultivar Florakirk foi a que produziu forragem com teor de PB mais elevado $(\mathrm{P}<0,05)$. Por outro lado, entre as gramíneas avaliadas, a cultivar Florico e o capim-estrela-africana foram as que proporcionaram menores teores de $\mathrm{PB}(\mathrm{P}<0,05)$. Os teores de $\mathrm{PB}$ da forragem residual foram muito semelhantes $(\mathrm{P}>0,05)$ nas duas dosagens de $\mathrm{N}: \mathrm{K}_{2} \mathrm{O}$ aplicadas e entre as cultivares forrageiras, sendo mais elevados na época das chuvas. Faz exceção para a cultivar Florakirk, que, nas chuvas, apresentou a forragem residual com teor de PB mais elevado que as demais (Tabela 2).

Os resultados alcançados para teores de PB 
Tabela 2 - Teores de PB na MS disponível e residual de cultivares de Cynodon, adubadas com 250:200 e 500:400 kg/ha de $\mathrm{N}: \mathrm{K}_{2} \mathrm{O}^{1}$

Table 2 - Percentage of CP and DM available and residual of Cynodon cultivars, fertilized with 250:200 e 500:400 kg/ha de N: $\mathrm{K}_{2} \mathrm{O}$ Cultivar Porcentagem de $\mathrm{PB}^{2}$

CP percentage

\begin{tabular}{|c|c|c|c|c|}
\hline & \multirow{2}{*}{\multicolumn{2}{|c|}{$\begin{array}{c}\text { Forragem disponível } \\
\text { Available forage }\end{array}$}} & & \\
\hline & & & \multicolumn{2}{|c|}{$\begin{array}{l}\text { Forragem residual } \\
\text { Residual forage }\end{array}$} \\
\hline & $\begin{array}{c}\text { Chuvas } \\
\text { Rainy period }\end{array}$ & $\begin{array}{c}\text { Seca } \\
\text { Dry period }\end{array}$ & $\begin{array}{c}\text { Chuvas } \\
\text { Rainy period }\end{array}$ & $\begin{array}{c}\text { Seca } \\
\text { Dry period }\end{array}$ \\
\hline & \multicolumn{4}{|c|}{$250: 200 \mathrm{~kg} / \mathrm{hade} \mathrm{N}: \mathrm{K}_{2} \mathrm{O}$} \\
\hline Florona & $12,9 b$ & $12,7 \mathrm{c}$ & $5,6 \mathrm{~b}$ & $5,0 \mathrm{a}$ \\
\hline Florakirk & $16,9 \mathrm{a}$ & $15,9 \mathrm{ab}$ & $8,0 \mathrm{a}$ & $5,1 \mathrm{a}$ \\
\hline Estrela africana & $9,1 \mathrm{c}$ & $8,7 d$ & $5,4 \mathrm{~b}$ & $4,7 \mathrm{a}$ \\
\hline Florico & $10,7 \mathrm{c}$ & $10,0 \mathrm{~d}$ & $5,6 b$ & $4,7 \mathrm{a}$ \\
\hline Média (Mean) & $12,4 \mathrm{~B}$ & $11,8 \mathrm{~B}$ & $6,1 \mathrm{~A}$ & $4,9 \mathrm{~A}$ \\
\hline & & & de $\mathrm{N}: \mathrm{K}_{2} \mathrm{O}$.. & \\
\hline Florona & $13,5 b$ & $14,9 \mathrm{~b}$ & $5,8 \mathrm{~b}$ & $5,2 \mathrm{a}$ \\
\hline Florakirk & $18,9 \mathrm{a}$ & $17,2 \mathrm{a}$ & $8,4 a$ & $5,0 \mathrm{a}$ \\
\hline Estrela africana & $11,3 \mathrm{c}$ & $10,1 d$ & $5,6 b$ & $4,6 a$ \\
\hline Florico & $11,8 \mathrm{bc}$ & $12,3 \mathrm{c}$ & $5,5 \mathrm{~b}$ & $5,0 \mathrm{a}$ \\
\hline Média (Mean) & $13,9 \mathrm{~A}$ & $13,6 \mathrm{~A}$ & $6,3 \mathrm{~A}$ & $4,9 \mathrm{~A}$ \\
\hline $\mathrm{CV}(\%)$ & 20,17 & 16,98 & 19,21 & 17,83 \\
\hline
\end{tabular}

${ }^{1}$ Média de dois anos de avaliação (Mean of two years of evaluation).

${ }^{2} \mathrm{Na}$ coluna, valores seguidos de diferentes letras minúsculas e médias seguidas de diferentes letras maiúsculas são diferentess entre si, pelo teste Tukey $(P<0,05)$ (In column, values followed by different letters small and means followed by different letters capital are different [P<.05] by Tukey test).

estão diretamente relacionados com a relação folha:colmo das plantas forrageiras estudadas. Aquelas que proporcionaram forragem com teores de PB mais elevados foram as que apresentaram maior $(\mathrm{P}<0,05)$ relação folha:colmo.

Mislevy (1995) registrou menor teor de PB na forragem da cultivar Florakirk, enquanto Mislevy (1989a, 1989b) verificou que o teor protéico da cultivar Florona é semelhante ao dos dados apresentados no presente trabalho, enquanto o da cultivar Florico é mais elevado. A semelhança do que ocorreu com os acúmulos de MS, nos trabalhos de Alvim et al. (1998, 1999), doses de $\mathrm{N}: \mathrm{K}_{2} \mathrm{O}$ (relação $\mathrm{N}: \mathrm{K}_{2} \mathrm{O}=0,8$ ) e intervalos de cortes interferiram nos teores de $\mathrm{PB}$ na forragem do Coastcross e do Tifton 85. Para o coastcross, os teores de PB variaram de 10,3 a $23,4 \%$ e para a cultivar Tifton 85 , de 5 a $23 \%$, respectivamente, na freqüência de cortes de duas semanas e sem adubação nitrogenada e na freqüência de cortes de sete semanas e adubação $\mathrm{N}: \mathrm{K}_{2} \mathrm{O}$ de 600:480 kg/ha/ano. Os teores de PB alcançados no presente trabalho para a estrela-africana foram semelhantes aos obtidos em Cuba por Ramos et al. (1993). Estes autores também constataram efeitos positivos da aplicação de $\mathrm{N}$ e de $\mathrm{K}_{2} \mathrm{O}$ sobre o teor de proteína bruta na MS dessa gramínea.
Não se observaram efeitos significativos $(\mathrm{P}>0,05)$ das doses de $\mathrm{N}: \mathrm{K}_{2} \mathrm{O}$ aplicadas sobre a relação folhacolmo nas forragens disponível e residual das gramíneas avaliadas. Por outro lado, notou-se que essa relação folha:colmo foi maior $(\mathrm{P}<0,05)$ na época das chuvas do que na época da seca. Em ambas dosagens de $\mathrm{N}: \mathrm{K}_{2} \mathrm{O}$ tanto na época das chuvas quanto na seca, as cultivares Florakirk e Florona apresentaram melhor $(\mathrm{P}<0,05)$ relação folha-colmo. A relação folha:colmo dessas duas cultivares foi bastante expressiva, também na forragem residual, demonstrando que, no caso dessas plantas forrageiras, os animais em pastejo não são capazes de selecionar apenas as folhas das cultivares Florakirk e Florona, ingerindo também o colmo, que apresenta boa digestibilidade (Tabelas 3 e 4).

Não foi observado efeito do $\mathrm{N}: \mathrm{K}_{2} \mathrm{O}$ sobre a DIVMS $(\mathrm{P}>0,05)$, nas quatro plantas forrageiras avaliadas. Tanto para a planta inteira quanto para o colmo, a cultivar Florakirk foi a que apresentou melhor DIVMS $(\mathrm{P}<0,05)$, enquanto o capim-estrelaafricana foi a menos digestível $(P<0,05)$. A DIVMS do colmo da cultivar Florakirk foi bastante expressiva, caracterizando a alta qualidade dessa planta forrageira. A forragem das cultivares Florona e Florico apresentaram DIVMS intermediária. No geral, a 
Tabela 3 - Relação folha:colmo na forragem disponível e residual de cultivares de Cynodon, adubadas com 250:200 e $500: 400 \mathrm{~kg} / \mathrm{ha}$ de $\mathrm{N}: \mathrm{K}_{2} \mathrm{O}^{1}$

Table 3 - Leaf:stem ratio in available and residual forage of cynodon cultivars, fertilized with 250:200 and 500:400 kg/ha of N: $\mathrm{K}_{2} \mathrm{O}$ Cultivar Relação folha:colmo ${ }^{2}$

Leaf-stem ratio

\begin{tabular}{|c|c|c|c|}
\hline \multicolumn{2}{|c|}{$\begin{array}{c}\text { Forragem disponível } \\
\text { Available forage }\end{array}$} & \multicolumn{2}{|c|}{$\begin{array}{l}\text { Forragem residual } \\
\text { Residual forage }\end{array}$} \\
\hline Chuvas & Seca & Chuvas & Seca \\
\hline Rainy period & Dry period & Rainy period & Dry period \\
\hline \multicolumn{4}{|c|}{$250: 200 \mathrm{~kg} / \mathrm{hade} \mathrm{N}: \mathrm{K}_{2} \mathrm{O}$. } \\
\hline $1,3 \mathrm{a}$ & $1,1 \mathrm{a}$ & $0,7 \mathrm{a}$ & $0,5 \mathrm{a}$ \\
\hline $1,5 \mathrm{a}$ & $1,2 \mathrm{a}$ & $0,6 a$ & $0,6 \mathrm{a}$ \\
\hline $0,9 b$ & $0,8 b$ & $0,3 b$ & $0,2 b$ \\
\hline $1,0 \mathrm{~b}$ & $0,8 \mathrm{~b}$ & $0,2 b$ & $0,2 b$ \\
\hline \multicolumn{4}{|c|}{$\ldots \ldots \ldots . .500: 400 \mathrm{~kg} / \mathrm{ha}$ de $\mathrm{N}: \mathrm{K}_{2} \mathrm{O} \ldots \ldots}$. \\
\hline $1,4 \mathrm{a}$ & $1,1 \mathrm{a}$ & $0,6 a$ & $0,6 a$ \\
\hline $1,5 \mathrm{a}$ & $1,1 \mathrm{a}$ & $0,7 \mathrm{a}$ & $0,6 \mathrm{a}$ \\
\hline $0,9 b$ & $0,6 b$ & $0,3 b$ & $0,2 b$ \\
\hline $0,8 b$ & $0,6 b$ & $0,3 b$ & $0,2 b$ \\
\hline 21,35 & 16,93 & 13,39 & 16,02 \\
\hline
\end{tabular}

Florona

Florakirk

Estrela africana

Florico

Florona

Florakirk

Estrela africana

Florico

CV (\%)

${ }^{1}$ Média de dois anos de avaliação (Mean of two years of evaluation).

$2 \mathrm{Na}$ coluna, valores seguidos de diferentes letras são diferentes entre si, pelo teste Tukey $(\mathrm{P}<0,05)($ In column, values followed by different letters are different $[P<.05]$ by Tukey test).

Tabela 4 - Digestibilidade in vitro da matéria seca (DIVMS) disponível e residual e do colmo de cultivares de Cynodon, adubadas com 250:200 e 500:400 kg/ha de $\mathrm{N}: \mathrm{K}_{2} \mathrm{O}^{1,2}$

Table 4 - In vitro dry matter digestibility (IVDMD) in available and residual forage and stem in Cynodon cultivars, fertilized with $250: 200$ e $500: 400 \mathrm{~kg} / \mathrm{ha}$ de $\mathrm{N}: \mathrm{K}_{2} \mathrm{O}$

Cultivar $\operatorname{DIVMS}(\%)^{3}$

$\operatorname{IVDMD}(\%)$

\begin{tabular}{|c|c|c|c|c|}
\hline \multicolumn{5}{|c|}{$\begin{array}{l}\operatorname{DIVMS}(\%)^{3} \\
\operatorname{IVDMD}(\%)\end{array}$} \\
\hline \multicolumn{3}{|c|}{$\begin{array}{c}\text { Forragem disponível } \\
\text { Available forage }\end{array}$} & \multicolumn{2}{|c|}{$\begin{array}{l}\text { Forragem residual } \\
\text { Residual forage }\end{array}$} \\
\hline \multirow{2}{*}{\multicolumn{2}{|c|}{$\begin{array}{c}\text { Chuvas } \\
\text { Rainy period }\end{array}$}} & \multirow{2}{*}{$\begin{array}{c}\text { Seca } \\
\text { Dry period }\end{array}$} & Chuvas & Seca \\
\hline & & & Rainy period & Dry period \\
\hline \multicolumn{5}{|c|}{$.250: 200 \mathrm{~kg} / \mathrm{ha}$ de $\mathrm{N}: \mathrm{K}_{2} \mathrm{O}}$. \\
\hline $59,9 \mathrm{a}$ & $(38,2) \mathrm{b}$ & $56,2 \mathrm{a} \quad(31,2) \mathrm{b}$ & $40,3 \mathrm{a}$ & $36,0 \mathrm{a}$ \\
\hline $64,7 \mathrm{a}$ & $(47,3) \mathrm{a}$ & $60,0 \mathrm{a}(43,4) \mathrm{a}$ & $42,1 \mathrm{a}$ & $40,2 \mathrm{a}$ \\
\hline $51,6 b$ & $(26,9) \mathrm{cd}$ & $48,2 \mathrm{~b} \quad(19,3) \mathrm{c}$ & $33,5 b$ & $29,4 b$ \\
\hline $60,4 \mathrm{a}$ & $(39,1) \mathrm{b}$ & $57,2 \mathrm{a}(32,9) \mathrm{b}$ & $40,9 \mathrm{a}$ & $38,8 \mathrm{a}$ \\
\hline \multicolumn{5}{|c|}{. } \\
\hline $61,1 \mathrm{a}$ & $(31,3) \mathrm{c}$ & $57,3 \mathrm{a} \quad(33,2) \mathrm{b}$ & $41,0 \mathrm{a}$ & $36,1 \mathrm{a}$ \\
\hline $65,3 \mathrm{a}$ & $(44,0) \mathrm{a}$ & $60,7 \mathrm{a} \quad(39,9) \mathrm{a}$ & $43,2 \mathrm{a}$ & $40,1 \mathrm{a}$ \\
\hline $50,7 \mathrm{~b}$ & $(23,1) \mathrm{d}$ & $45,7 b(20,2) c$ & $34,2 b$ & $30,6 b$ \\
\hline $60,0 \mathrm{a}$ & $(34,5) \mathrm{bc}$ & $58,9 \mathrm{a} \quad(32,7) \mathrm{b}$ & $41,4 \mathrm{a}$ & $40,3 \mathrm{a}$ \\
\hline 16,36 & $(20,19)$ & $19,43 \quad(21,78)$ & 14,27 & 17,11 \\
\hline
\end{tabular}

Florona

Florakirk

Estrela africana

Florico

Florona

Florakirk

Estrela africana

Florico

CV $(\%)$

${ }^{1}$ Média de dois anos de avaliação (Mean of two years of evaluation).

2 Valores entre parênteses correspondem à DIVMS do colmo (Values in brackts refers the IVDMD of stem).

${ }^{3} \mathrm{Na}$ coluna, valores seguidos de letras distintas diferem entre si, pelo teste Tukey $(\mathrm{P}<0,05)$ (In column, values followed by different letters are different $[P<.05]$ by Tukey test). 
DIVMS na época das chuvas foi mais elevada que a da época da seca, enquanto a DIVMS disponível foi maior que a da massa seca residual (Tabela 4).

As DIVMS registradas neste trabalho foram mais elevadas que as observadas por Mislevy (1989a, $1989 \mathrm{~b}$ e 1995). Possivelmente, isso se deve à diferença no método de avaliação. No presente trabalho, além do pastejo, a fertilização nitrogenada e potássica foi realizada em dosagens de $\mathrm{N}$ mais elevadas que nos trabalhos daquele autor. Herrera \& Hernandez (1988) observaram maior DIVMS do Coastcross durante a época da seca, ao contrário do que se observou no presente trabalho. Esses autores verificaram que a porcentagem de lignina e celulose na forragem era maior na época das chuvas, comprometendo a digestibilidade da forragem nessa época do ano. Herrera \& Hernandez (1986) verificaram que a adubação nitrogenada fez reduzir a porcentagem de lignina e celulose na parede celular do coastcross, com conseqüente aumento na digestibilidade dessa planta forrageira.

Ao final de dois anos de avaliações, foi observada baixa população de plantas invasoras nos piquetes da cultivar Florona e do capim-estrela-africana, ao contrário do que se constatou nos piquetes das cultivares Florico e Florakirk, independente das dosagens de $\mathrm{N}: \mathrm{K}_{2} \mathrm{O}$ (Tabela 5). Considerando que as gramíneas avaliadas são adequadas para formação de pastagens em áreas de várzea, onde naturalmente ocorrem inúmeras espécies de plantas daninhas (Pereira, 1990), a baixa população de plantas invasoras nas pastagens da cultivar Florona e do capim-estrela-africana é de muita importância, devendo ser considerado como fator positivo no momento de se decidir sobre a planta forrageira a ser introduzida em sistema de produção de leite.

Diante dos resultados obtidos, o capim-estrelaafricana não é o mais recomendado para sistemas de produção de leite em pastagem, quando se tratar de vacas com potencial para produção mais elevado, já que proporciona forragem com qualidade inferior. Também a cultivar Florico não deve ser indicada para sistemas de produção de leite, uma vez que produz pouca quantidade de forragem. A quantidade de folha na cultivar Florakirk é muito expressiva, o que caracteriza essa forrageira como sendo de alta qualidade. No entanto, como no período da seca produz pouca forragem, essa cultivar não constitui opção viável para formar pastagens em sistemas de produção de leite em pastagem, na Região Sudeste. Contudo, aproveitando a sua expressiva produção de forragem na época das chuvas e sua a elevada qualidade, a cultivar Florakirk pode constituir alternativa para produção de feno. Desta forma, associando a produção com a qualidade da forragem, dentre as cultivares avaliadas, a cultivar Florona é a mais adequada para ser incluída em sistemas de produção de leite a pasto.

Tabela 5 - Produção de MS de plantas invasoras em pastagens de cultivares de Cynodon, adubadas com 250:200 e $500: 400 \mathrm{~kg} / \mathrm{ha}$ de $\mathrm{N}: \mathrm{K}_{2} \mathrm{O}$

Table 5 - Dry matter yield of weeds plants of cynodon cultivars pastures, fertilized with 250:200 and 500:400 kg/ha of N:K $\mathrm{K}_{2} \mathrm{O}$

\begin{tabular}{|c|c|c|c|c|}
\hline \multirow[t]{4}{*}{ Cultivar } & \multicolumn{4}{|c|}{$\begin{array}{c}\text { Produção de MS }(\mathrm{kg} / \mathrm{ha})^{2} \\
\text { Dry matter yield }(\mathrm{kg} / \mathrm{ha})\end{array}$} \\
\hline & Inicial & Final $^{1}$ & Inicial & Final $^{1}$ \\
\hline & Initial & Final & Initial & Final \\
\hline & \multicolumn{2}{|c|}{$250: 200 \mathrm{~kg} / \mathrm{h}$ a de $\mathrm{N}: \mathrm{K}_{2} \mathrm{O}$} & \multicolumn{2}{|c|}{$500: 400 \mathrm{~kg} / \mathrm{ha}$ de $\mathrm{N}: \mathrm{K}_{2} \mathrm{O}$} \\
\hline Florona & $192 \mathrm{a}$ & $312 \mathrm{c}$ & $97 b$ & $92 b$ \\
\hline Florakirk & $103 c$ & $1.287 \mathrm{~b}$ & $112 \mathrm{ab}$ & $1.499 \mathrm{a}$ \\
\hline Estrela africana & $129 b c$ & $206 c$ & $142 \mathrm{a}$ & $200 b$ \\
\hline Florico & $156 b$ & $1.817 \mathrm{a}$ & $124 \mathrm{ab}$ & $1.658 \mathrm{a}$ \\
\hline $\mathrm{CV}(\%)$ & 13,29 & 16,28 & 19,47 & 18,03 \\
\hline
\end{tabular}

${ }^{1}$ Médias obtidas de dois anos de pastejo - dois períodos de seca e dois períodos de chuvas (Means obtained of two years of grazing - two rainy periods and two dry periods).

$2 \mathrm{Na}$ coluna, valores seguidos de letras distintas diferem entre si, pelo teste de Tukey $(\mathrm{P}<0,05)($ In column, values followed by differents letters are different $[P<.05]$ by Tukey test). 


\section{Conclusões}

Em relação à aplicação de $250: 200 \mathrm{~kg} / \mathrm{ha} /$ ano de $\mathrm{N}: \mathrm{K}_{2} \mathrm{O}$, a aplicação de $500: 400 \mathrm{~kg} / \mathrm{ha} /$ ano de $\mathrm{N}: \mathrm{K}_{2} \mathrm{O}$ não aumenta a produção de MS e nem eleva os teores de proteína bruta e a DIVMS, tanto na época das chuvas quanto na seca.

A cultivar Florakirk é a gramínea que proporciona maior quantidade anual de massa seca, com teores de PB e DIVMS mais elevados. Contudo, a sua produção de forragem na época da seca é baixa, comprometendo a sua indicação como opção para sistemas de produção de leite em pastagem.

A cultivar Florona apresenta potencial para produzir elevada quantidade de forragem de boa qualidade e proporciona a melhor distribuição de forragem ao longo do ano. Assim, é indicada como alternativa viável para formação de pastagens e ser incluída em sistemas de produção de leite em pastagem.

O capim-estrela-africana também proporciona elevada quantidade de forragem, mas com baixos teores de PB e de DIVMS. Assim, é mais adequada para alimentar vacas de menor potencial de produção.

A cultivar Florico não se adapta adequadamente na região da Zona da Mata de Minas Gerais, uma vez que sua produção de forragem é muito baixa.

\section{Literatura Citada}

ALVIM, M.J.; XAVIER, D.F.; BOTREL, M.A. et al. Resposta do "Coastcross" (Cynodon dactylon (L.) Pers.) a diferentes doses de nitrogênio e intervalos de cortes. Revista Brasileira de Zootecnia, Viçosa, MG, v.27, n.5, p. 829-836, 1998.

ALVIM, M.J.; XAVIER, D.F.; VERNEQUE, R.S. et al. Resposta do Tifton 85 a doses de nitrogênio e intervalos de cortes. Pesquisa Agropecuária Brasileira, v.34, n.12, p.23452352, 1999.

ASSOCIATION OF OFFICIAL ANALYTICAL CHEMISTS AOAC. Official methods of analysis. 14.ed. Washington, D.C.: 1984. $1141 \mathrm{p}$.

BOTREL, M.A.; ALVIM, M.J.; MOZZER, O.L. Avaliação agronômica de gramíneas forrageiras sob pastejo. Pesquisa Agropecuária Brasileira, v.22, n.10, p.1019-1025, 1987.

BOTREL, M.A.; NOVAES, L.P.; ALVIM, M.J. Características forrageiras de algumas gramíneas tropicais. Juiz de Fora: Embrapa-CNPGL, 1998. 35p. (EMBRAPA-CNPGL. Documentos, 66)
EDYE, L.A. Comparison of twenty-seven introduced grasses in two dry tropical environment in Northern Queensland. Australian Journal Experimental Agricultural and Animal Husbandry, v.15, n.77, p. 788-802, 1975.

GARDNER, A.L. Evaluación por corte y por pastoreo en parcelas pequeñas: comparación de resultados. In: PALADINES, O; LASCANO, C. Germoplasma forrajero bajo pastoreo en pequeñas parcelas. Cali: CIAT, 1983. p.107-120.

HERNANDEZ, M.; CÁRDENAS, H. Respuesta del pasto estrela jamaicano a niveles de NPK en un suelo ferralítico cuarcítico. Pastos e Forrajes, v.13, n.4, p.273 - 278, 1990.

HERRERA, R.S.; HERNANDÉZ, Y. Efecto de la fertilización nitrogenada en la calidad de Cynodon dactylon cv. Coastcross1. III. Componentes estructurales y digestilidadad. Pastos y Forrajes, v.9, n.1, p.65-70, 1986.

HERRERA, R.S., HERNANDÉZ, Y. Efecto de la edad del rebrote en algunos indicadores de la calidad de la bermuda cruzada-1. II. Componentes estructurales y digestibilidad de la massa seca. Pastos y Forrajes, v.11, n.2, p.177 182, 1988.

MISLEVY, P. Florakirk bermudagrass. Flórida: University of Florida, 1995. 9p. (Circular, S 395)

MISLEVY, P. Florico stargrass. Flórida, USA: University of Florida, 1989b. 15p. (Circular, S 361)

MISLEVY, P. Florona stargrass. Flórida: University of Florida, 1989a. 13p. (Circular, S 362)

PEREIRA, J.R. Plantas invasoras de pastagens. In: CURSO DE PECUÁRIA LEITEIRA. Coronel Pacheco: EMBRAPACNPGL, 1990. 31p. (Documentos, 14)

RAMOS, N.; HERRERA, R.S.; CURBELO, F. Efecto de la fertilizacón nitrogenada en espécies y variedades de Cynodon en suelo ferralítico rojo típico. II. Composición química y eficiencia de utilización del N. Revista Cubana de Ciência Agrícola, v.27, n.4, p.239-248, 1993.

TILLEY, J.M.A.; TERRY, R.A. A two stage technique for the in vitro digestion of forage crops. Journal of the British Grassland Society, v.18, n.1, p.104-111, 1963.

VILELA, D.; ALVIM, M.J.; CAMPOS, O.F. et al. Produção de leite de vacas Holandesas em confinamento ou em pastagem de Coastcross. Revista da Sociedade Brasileira de Zootecnia, v.25, n.6, p.1228-1244, 1996. 